\title{
Ultrasound-guided lateral sagittal infraclavicular block in a patient with flexion contracture
}

\author{
Onur Palabiyik $^{1 *}$
}

Dear Editor,

Lateral sagittal infraclavicular block (LSIB) is a technique of regional anesthesia that is frequently used for anesthesia and analgesia in lower arm surgery. After ultrasound (US) had started to be used in the practice of anesthesia, peripheral nerve blocks (PNBs) could be applied more easily and with less risk. Besides, US emerges as an essential source for PNBs in cases of the nerve stimulator is not possible to use. In this present, we showed that US-guided LSIB was successfully applied for finger amputation in a patient with flexion contracture of the left hand due to previous cerebrovascular disease (CVD), which we do not be able to correctly provide the muscle response to nerve stimulator.

An 80-years female patient was scheduled for finger amputation. The patient had a flexion contracture in her left hand, which had not motor activities, as sequel due to the previous CVD for seven years. The patient had edema and laceration advancing to bone tissue, which were caused by the compression of the two rings, in her third finger of the left hand (Figure). The patient had normal physical examination and laboratory findings. To provide surgical anesthesia and postoperative analgesia, US-guided LSIB was decided. Following informed consent, electrocardiography, non-invasive blood pressure, and pulse oximeter were instituted in the operation room. Intravenous (IV) access was provided. The patient was sedated with $2 \mathrm{mg}$ midazolam intravenously and lied in the supine position with left arm adducted and turned her head to opposite side. After all aseptic precautions, US probe was placed as in-plane technique near the entry point of the needle where is stated as the intersection between the clavicle and the coracoid process. The axillary artery and chords of nerves were identified. A $100 \mathrm{~mm} 21 \mathrm{G}$ nerve stimulation needle was introduced caudally in a sagittal plane and $45^{\circ}$ from the skin on a horizontal plane as in the same plane with the probe. After $2 \mathrm{ml}$ of $0.25 \%$ bupivacaine and $1 \%$ lidocaine mixture was given under the skin, the needle was advanced and placed through the posterior to the axillary artery. We were reached to the goal at a depth of $5 \mathrm{~cm}$ from the skin. After no blood within negative aspiration had seen, $15 \mathrm{ml}$ of $0.25 \%$ bupivacaine and $1 \%$ lidocaine mixture were injected intermittently.
The spread of local anesthetic mixture as surrounding the artery was observed during the injection period. When the adequate sensory block was achieved, the surgery was allowed. The surgery lasted 40 minutes was uneventfully completed. The patient had not needed additional analgesia and sedation during the surgical procedure. First analgesic requirement time was about 8 hours. The patient was discharged uneventfully.

The infraclavicular block is suggested as the safer and more effective technique in PNB for lower arm surgery (1). LSIB, which was developed by Klaastad et al. (2), is often preferred because of applying easily and with less risk of complication. LSIB is applied with nerve stimulator or US. US provides to view the nerves and the advancing of the needle during the injection that obtains increasing the success rate of the block and reducing the complications $(3,4)$. By visualizing the spread of local anesthetic with US, PNBs can be applied with low dose local anesthetic.

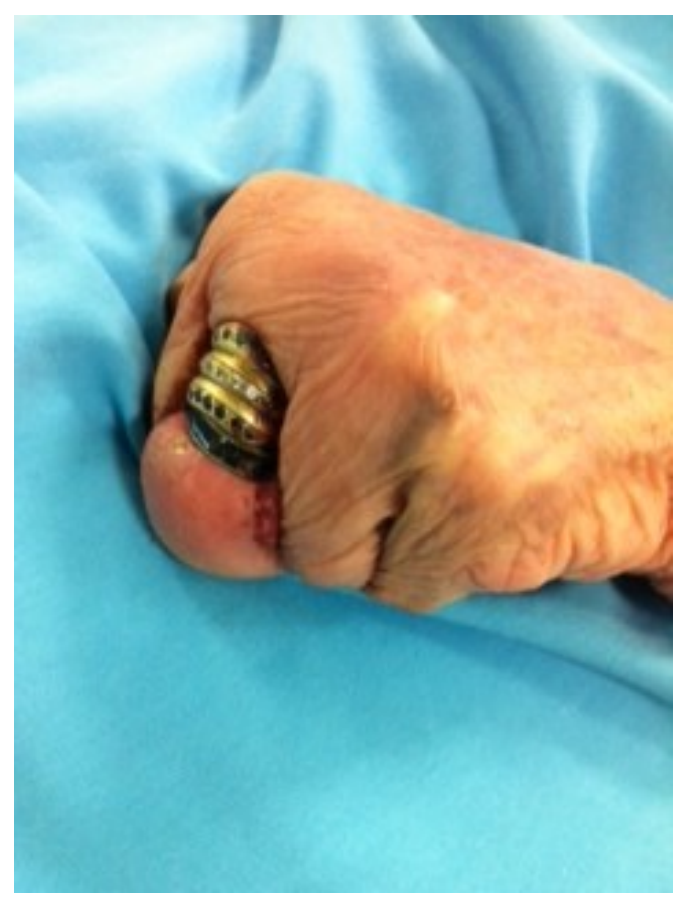

Figure: The patient's left hand with flexion contracture like clenched fist 
Additionally, PNBs can be applied only with US in some conditions; such as nerve stimulation is not possible, muscle response to nerve stimulation could not be accurately obtained and appropriate position of patient was not available for PNB (5). We applied a successful anesthesia with USG-guided LSIB. As a result, US-guided LSIB may be applied an effective and safe anesthesia in lower arm surgery in the patient with a sequel of the previous CVD.

\section{References}

1. Chin KJ, Alakkad H, Adhikary SD, Singh M. Infraclavicular brachial plexus block for regional anaesthesia of the lower arm. Cochrane Database Syst Rev. 2013; 8:CD005487. doi: 10.1002/14651858.CD005487.pub3.

2. Klaastad $\varnothing$, Smith HJ, Smedby O, Winther-Larssen EH, Brodal $\mathrm{P}$, Breivik $\mathrm{H}$, and et al. A novel infraclavicular brachial plexus block: the lateral and sagittal technique, developed by magnetic resonance imaging studies. Anesth Analg 2004; 98(1):252-6

3. Gurkan Y, Acar S, Solak M, Toker K. Comparison of nerve stimulation vs. ultrasound-guided lateral sagittal infraclavicular block. Acta Anaesthesiol Scand 2008; 52(6):851-5

4. Trabelsi W, Amor MB, Lebbi MA, Romdhani C, Dhahri $\mathrm{S}$, Ferjani M. Ultrasound does not shorten the duration of procedure but provides a faster sensory and motor block onset in comparison to nerve stimulator in infraclavicular brachial plexus block. Korean J Anesthesiol. 2013; 64(4):327-33.

5. Kus A, Gurkan Y, Gok CN, Solak M, Toker K. Ampute üst ekstremitede ultrason ile infraklavikular blok. Ağrı $2010 ; 22(3): 134-6$

Copyright (C) 2014 The Author(s); This is an open-access article distributed under the terms of the Creative Commons Attribution License (http://creativecommons.org/licenses/by/4.0), which permits unrestricted use, distribution, and reproduction in any medium, provided the original work is properly cited. All Rights reserved by international journal of Medical Science and Discovery and Lycians Press Inc. 